\title{
CẮT U NHẦY NHĨ TRÁI KHỔNG LỒ BẦNG PHƯƠNG PHÁP NỘI SOI TOÀN Bộ KHÔNG ROBOT HỖ TRỢ
}

\author{
Đặng Quang Huy*, Trần Đắc Đại*, Nguyễn Toàn Thắng*, Nguyễn Thị Hảo*, Lê Ngoc Thành*
}

\section{TÓM TẮT}

Chưa có báo cáo về áp dụng phẫu thuật nội soi toàn bộ trong điều trị u nhầy nhĩ trái lớn. Bệnh nhân nữ 62 tuổi với khối u nhầy nhĩ trái lớn gây triệu chứng hẹp van hai lá nặng, phù phổi cấp, đã được phẫu thuật thành công bằng phương pháp nội soi toàn bộ không robot hỗ trợ qua 4 lỗ trocar nhỏ (3 trocar $5 \mathrm{~mm}$, và 1 trocar $12 \mathrm{~mm})$.Bệnh nhân sớm hồi phục và hài lòng với những lợi điểm về thẩm mỹ.

Keywords: $u$ nhầy trong tim, phẫu thuật tim nội soi toàn bộ, phẫu thuật robot.

\section{I. ĐĂT VẤN ĐỀ}

U nhầy là dạng u phổ biến nhất, chiếm từ 30$50 \%$ bệnh lý u tiên phát tại tim, hầu hết u nhầy là $\mathrm{u}$ ở nhĩ trái với kích thước từ $0.4-6 \mathrm{~cm}$. ${ }^{1}$ Phương pháp điều trị phổ biến là cắt $\mathrm{u}$ qua đường mổ cưa dọc xương ức. Mặc dù một vài trường hợp u nhầy nhĩ trái lớn gây triệu chứng hẹp van hai lá (VHL) và tăng áp lực động mạch phổi (ĐMP) đã được thông báo; chưa có một báo cáo nào về trường hợp u nhầy lớn $>10 \mathrm{~cm}$ gây hẹp nặng VHL được phẫu thuật bằng phương pháp nội soi toàn bộ (NSTB). Trong bài này, chúng tôi mô tả 1 trường hợp $\mathrm{u}$ nhầy khổng lồ gây triệu chứng giả hẹp VHL, tăng áp lực ĐMP đã được phẫu thuật thành công bằng phương pháp NSTB không robot hỗ trợ.

\section{TRƯỜNG HỢP BÊNH}

Bệnh nhân $(\mathrm{BN})$ nữ 62 tuổi có triệu chứng khó thở khi gắng sức, khó thở khi nằm và đau tức ngực trái trước vào viện 1 tháng. $\mathrm{BN}$ vào viện trong tình trạng cấp cứu: khó thở nhiều, không nằm được đầu bằng, đau tức ngực trái, ran ẩm rãi rác hai phổi. $\mathrm{BN}$ được chẩn đoán phù phổi cấp do hẹp VHL, được điều trị nội khoa tích cực bằng thở oxy mũi, lợi tiểu tiêm tĩnh mạch và an thần, triệu chứng cải thiện sau 30 phút. Siêu âm (SA) tim qua thành ngực được thực hiện ngay khi BN ổn định phát hiện một khối u rất lớn trong nhĩ trái, kích thước $150 * 66^{*} 30 \mathrm{~mm}$, có chân bám với đường kính khoảng $20 \mathrm{~mm}$ vào vách liên nhĩ (VLN) tại vị trí tương ứng với hố bầu dục. Khối u rất di động, di chuyển qua VHL vào thất trái trong thì tâm trương gây hẹp VHL với chênh áp
$16 \mathrm{mmHg}$. Thất phải giãn, van ba lá (VBL) hở vừa, áp lực ĐMP $58 \mathrm{mmHg}$.

$\mathrm{BN}$ được mổ cấp cứu bằng phương pháp NSTB không có robot hỗ trợ. Người bệnh được đặt ở tư thế nằm ngửa, hai tay dọc theo thân người, gây mê thông thường với nội khí quản một nòng. Tuẩn hoàn ngoài cơ thể (THNCT) ngoại vi được thiết lập với ống thông động mạch (ĐM) đùi được đặt gián tiếp qua đoạn mạch Dacron số 8; trong khi đó ống thông tĩnh mạch chủ (TMC) trên và $\mathrm{TMC}$ dưới được đặt qua tĩnh mạch $(\mathrm{TM})$ cảnh trong và $T M$ đùi theo phương pháp Seldinger. 4 trocar được thiết lập trên ngực phải của $\mathrm{BN}$, bao gồm: 01 trocar $12 \mathrm{~mm}$ tại khoang liên sườn (KLS) 5 đường nách trước cho tay làm việc chính, 01 trocar $5 \mathrm{~mm}$ tại KLS 4 đường nách giữa cho tay làm việc phụ, 01 trocar $5 \mathrm{~mm}$ tại KLS 5 đường nách giữa cho camera và 01 trocar $5 \mathrm{~mm}$ tại KLS 6 đường nách giữa cho đường hút máu về.

Sau khi thắt TMC trên, kim gốc $\mathrm{DMC}$ được đặt bằng cách chọc qua thành trước ngực phải. Bảo vệ cơ tim bằng dung dịch HTK xuôi dòng qua gốc ĐMC sau khi ĐMC được cặp lại bằng clamp Chitwood. Tiếp cận u qua đường nhĩ phải, VLN được cắt quanh hố bầu dục (vị trí chân khối $\mathrm{u}$ xác định trên $\mathrm{SA}$ trước mổ) sao cho đường cắt cách chân khối u $5 \mathrm{~mm}$. Khối u được lấy trọn vẹn ra khỏi nhĩ trái và được đưa ra khỏi lồng ngực qua trocar $12 \mathrm{~mm}$ sau khi đã được cho vào túi nylon. Lỗ thông liên nhĩ (TLN) sau đó được đóng lại sử dụng miểng vá nhân tạo, khâu vắt. Nhĩ phải được đóng hai lớp khâu vắt. Sau khi thả clamp Chitwood, tim đập lại nhịp xoang, đuổi khí qua kim gốc ĐMC.Ngừng THNCT và kết thúc cuộc mổ không gặp khó khăn gì. Thời gian chạy máy và thời gian cặp ĐMC lần lượt là 150 và 116 phút. SA trước khi ra viện vách liên nhĩ kín, VHL và $\mathrm{VBL}$ không hở. Kết quả giải phẫu bệnh là $\mathrm{u}$ nhầy. $\mathrm{BN}$ ra viện sau mổ 8 ngày không còn

\footnotetext{
* Trung tâm Tim mach Bệnh viện E

Nguời chịu trách nhiệm khoa họ: GS.TS. Lê Ngọc Thành

Ngày nhận bài: 01/08/2017 - Ngày Cho Phép Đăng: 07/08/2017

Phản Biện Khoa học: GS.TS. Bùi Đức Phú

PGS.TS. Đặng Ngoc Hùng
} 
những triệu chứng trước mổ và không có biến chứng về thần kinh, mạch máu. SA sau mổ 3 tháng không có dấu hiệu tái phát.

\section{BÀN LUÂN}

U nhầy nhĩ trái gây 3 nhóm triệu chứng phổ biến: (1) tắc mạch, (2) giả hẹp VHL và (3) triệu chứng thể tạng như: sốt, giảm cân, bệnh mô liên kết. Theo Cebrera cùng cộng sự, những khối u nhầy lớn, di động là nguyên nhân gây tai biến tắc mạch cấp và đột tử ở $15 \%$ trường hợp. $\mathrm{BN}$ của chúng tôi có khối u dạng polyp, chân cuống nhỏ hơn rất nhiều so với kích thước của $\mathrm{u}$, khối $\mathrm{u}$ đặc biệt di động vào sâu trong buồng thất trái trong thì tâm trương. Khối u như vậy có nguy cơ rất cao gây tắc mạch đồng thời gây hẹp lỗ VHL trong thì tâm trương dẫn tới phù phồi.

Thay thế cho phương pháp mổ truyền thống (cưa dọc xương ức), từ năm 2008 trở lại đây đã có một số công bố ca lâm sàng về áp dụng phẫu thuật NSTB với sự hỗ trợ của robot trong việc lấy bỏ các khối u nhầy trong tim, nhưng chủ yếu là những khối u nhỏ có đường kính $<7 \mathrm{~cm}$. Khó khăn gặp phải khi áp dụng NSTB cho những khối $\mathrm{u}$ có kích thước lớn đó là việc lấy u ra khỏi lồng ngực qua những lỗ trocar nhỏ sao cho u không bị đứt đoạn gây nguy cơ tái phát. Hầu hết tác giả sử dụng lỗ trocar có kích thước $2.5-3 \mathrm{~cm}$ để lấy những khối u $60-70 \mathrm{~mm}$. Trong báo cáo này, chúng tôi sử dụng lỗ trocar $12 \mathrm{~mm}$ để lấy khối $\mathrm{u}$ với kích thước $150 \mathrm{~mm}$. Để làm được như vậy chúng tôi dựa trên 2 thủ thuật nhỏ: (1) khối u được cho vào túi nylon trước khi lấy ra khỏi thành ngực và (2) mở rộng cân cơ của lỗ trocar

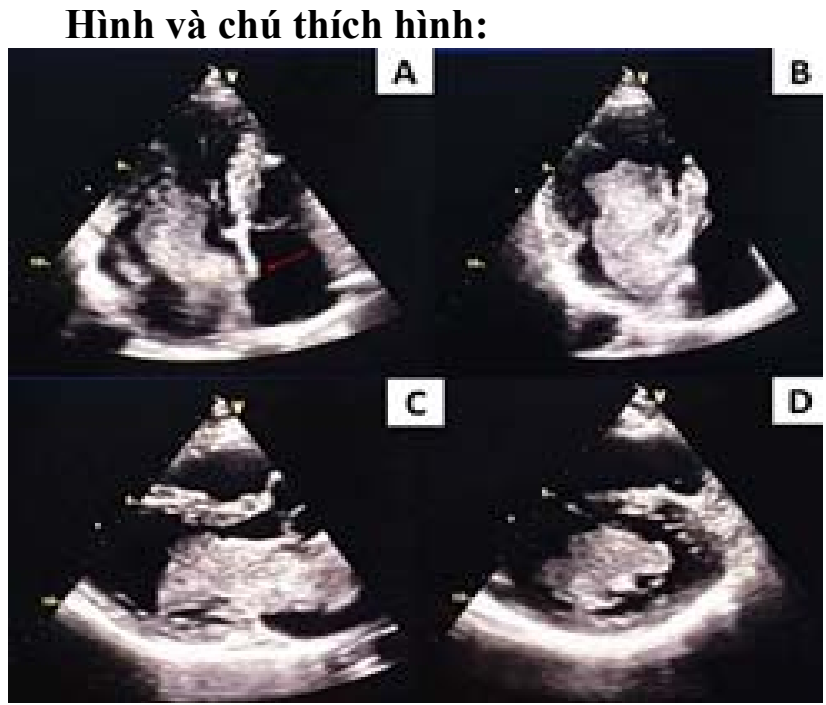

$12 \mathrm{~mm}$ dọc theo khoang liên sườn. Vì lớp da rất đàn hồi, khối u được lấy ra khỏi lồng ngực không bị nát và đứt đoạn.

Theo Shak cùng cộng sự, tỉ lệ tái phát của $u$ nhầy là $5 \%$ với những nguyên nhân được cho là do: u nhiều vị trí, cắt u không hết, reo rắc tế bào u trong mổ... Yếu tố kỹ thuật liên quan tới nguy cơ tái phát $\mathrm{u}$ được nhắc tới đó là việc cắt VLN quanh chân u. Mọi người đều thống nhất cắt VLN sao cho riềm cách chân $u$, điều này giúp giảm thiểu nguy cơ tái phát ngoại trừ những trường hợp $\mathrm{u}$ nằm sát van nhĩ thất hay rãnh nhĩ thất.

\section{TÀI LIÊU THAM KHẢO}

1. Zaher MF, Bajaj S, Habib M, et al. A giant left atrial myxoma. Case reports in medicine. 2014;2014:819052.

2. Cabrera H, Trindade e Silva LP, Gamboa C. Heart failure and syncope due to a giant atrial myxoma. Revista portuguesa de cardiologia : orgao oficial da Sociedade Portuguesa de Cardiologia $=$ Portuguese journal of cardiology : an official journal of the Portuguese Society of Cardiology. 2010;29(2):315-319.

3. Gao C, Yang M, Wang G, et al. Totally robotic resection of myxoma and atrial septal defect repair. Interactive cardiovascular and thoracic surgery. 2008;7(6):947-950.

4. Shah IK, Dearani JA, Daly RC, et al. Cardiac Myxomas: A 50-Year Experience With Resection and Analysis of Risk Factors for Recurrence. The Annals of thoracic surgery.100(2):495-500.

Hình 1. (A),(B): trên mặt cắt 4 buồng, u chiếm gần hết nhĩ trái, di động qua van hai lá trong thì tâm trương vào sâu trong buồng thất trái. Chân u (mũi tên mầu đỏ) bám vào vách liên nhĩ vị trí tương ứng hố bầu dục;

(C): trên mặt cắt trục dài cạnh ức, u lồi sâu vào thất trái và đường ra thất trái trong thì tâm trương;

(D): u chiếm hết diện tích lỗ van hai lá trên mặt cắt ngang qua vòng van hai lá. 


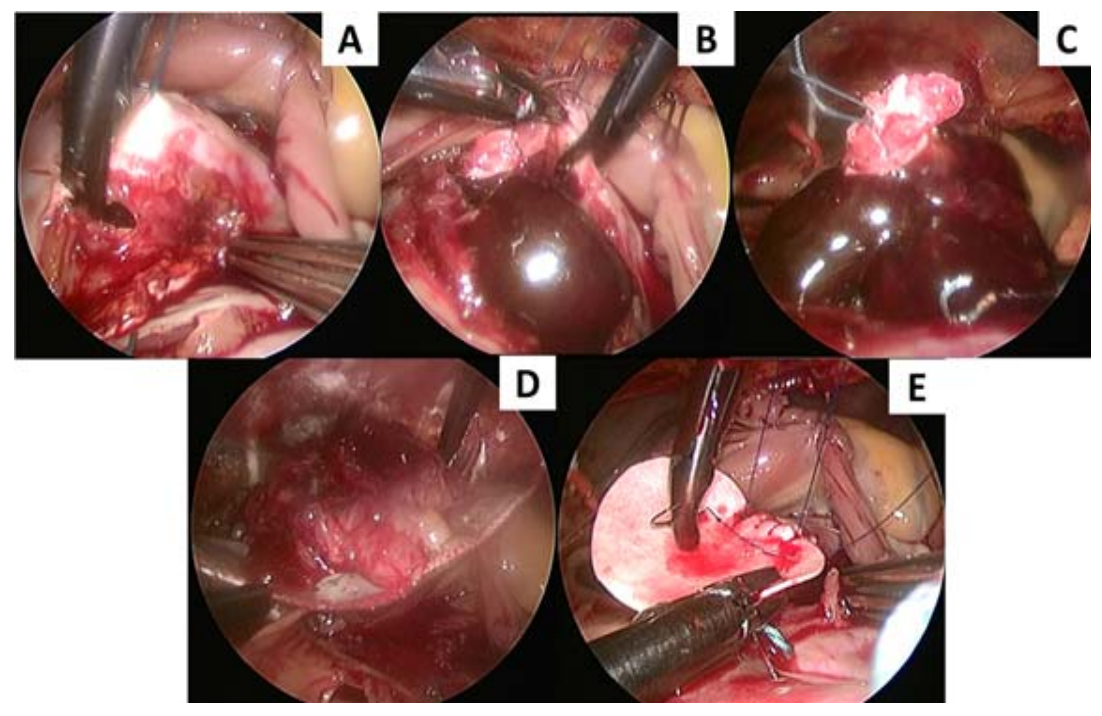

Hình 2. (A),(B): cắt vách liên nhĩ quanh chân khối u, cách chân khối u $5 \mathrm{~mm}$;

(C): lôi trọn vẹn khối u với cuống và phần riềm vách liên nhĩ đã cắt ra khỏi tim;

(D): khối u lớn được cho vào túi nylon trước khi lấy ra khỏi thành ngực;

(E): vá lỗ thông liên nhĩ sau đã lấy u.

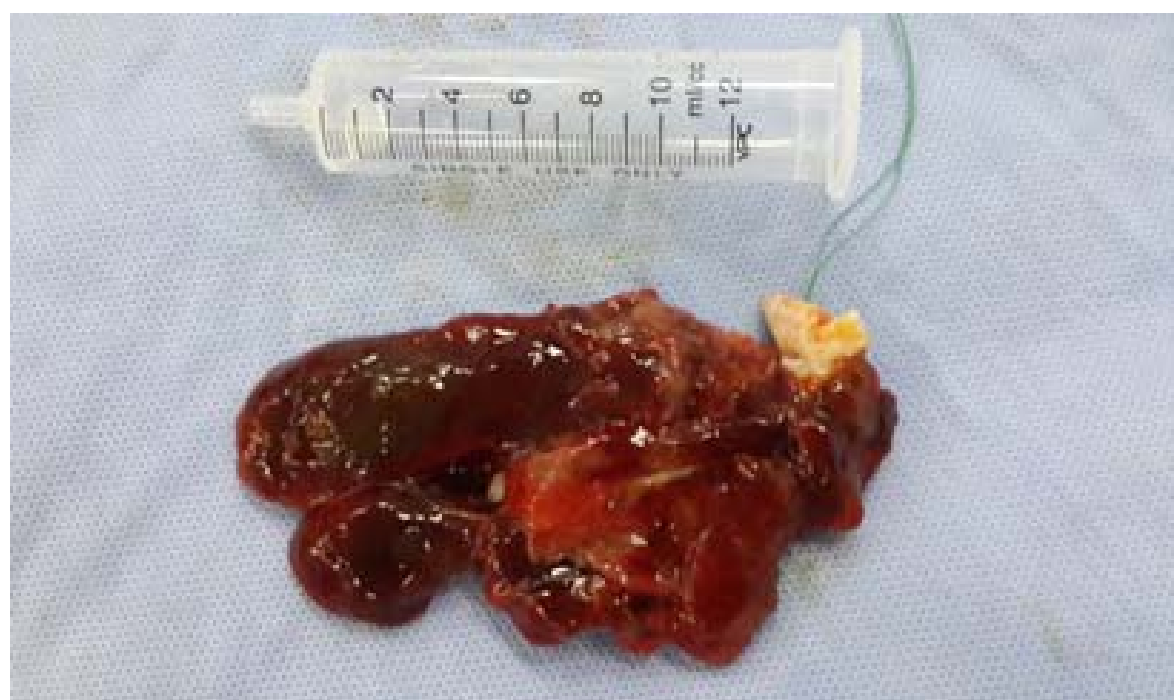

Hình 3. khối u nhầy lớn sau khi đã lấy ra khỏi người bệnh nhân.
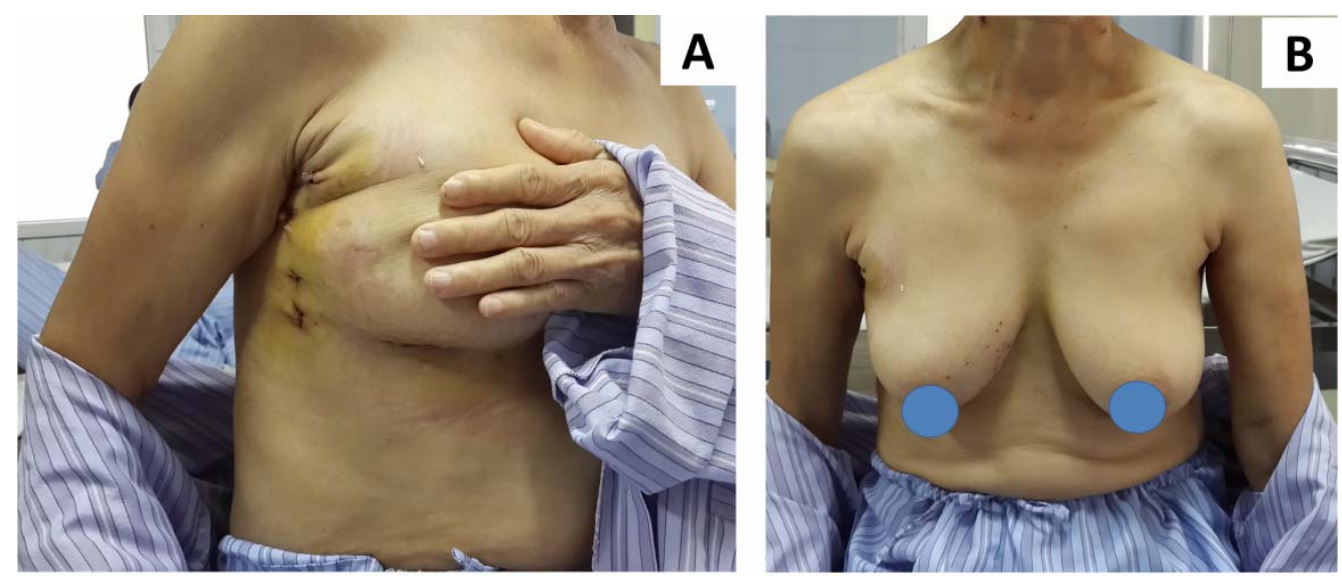

Hình 4. Hình sẹo mổ nhìn theo hướng trước bên $(\mathrm{A})$ và theo hướng trước sau $(\mathrm{B})$. 